\title{
A tool for assessing healthy food knowledge in 5-6-year-old Australian children
}

\author{
Dorota Zarnowiecki, James Dollman and Natalie Sinn* \\ Sansom Institute for Health Research, Division of Health Sciences, University of South Australia, GPO Box 2471, \\ Adelaide, SA 5001, Australia
}

Submitted 5 May 2010: Accepted 7 December 2010: First published online 3 February 2011

\begin{abstract}
Objective: In the early years of life, influential attributes are formed and may be difficult to change later in life. Early childhood is now recognised as a key target in the prevention of overweight and obesity, and the knowledge that children gain at this time about food and its health benefits may have an important influence on their dietary choices and preferences in later life. Therefore, an activity was designed using age-appropriate methods to assess nutrition knowledge of young children.

Design: The Healthy Food Knowledge Activity was developed using a list of thirty healthy and unhealthy foods and drinks generated from the Australian Guide to Healthy Eating.

Setting: The activity was conducted with individual children from reception classes of South Australian schools.

Subjects: Children aged 5-6 years undertook the activity in a pilot study ( $n 13)$ and in the main study ( $n$ 192).

Results: Pilot data indicated good test-retest reliability of the activity $(r=0 \cdot 84$, $P<0 \cdot 01)$. In the main study, there was a good distribution of scores with acceptable skewness and kurtosis statistics. A breakdown of responses indicated good face validity, with more obvious foods being more correctly classified.

Conclusions: Children as young as 5-6 years of age can correctly identify healthy foods, and this can be measured objectively. This activity also provides interesting insights regarding misconceptions about foods that could be attributed to influences such as media advertising and that can be addressed by educators of this age group.
\end{abstract}

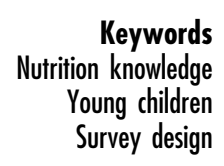

In the early years of life, important behaviours are formed and may be difficult to change later in life ${ }^{(1,2)}$. Therefore, early childhood is now recognised as a key target in the prevention of overweight and obesity, and the knowledge that children gain at this time about food and its health benefits can influence their dietary choices and preferences in later life ${ }^{(3,4)}$.

In making food choices, the influence of cognitive factors, such as knowledge about the health benefits and costs associated with foods, may be as important as food preferences and availability ${ }^{(2)}$. Studies involving schoolage children and adults have shown small but significant correlations between nutrition knowledge and eating behaviours, which indicates that, although not sufficient on its own, nutrition knowledge is a factor in making healthier food choices ${ }^{(5-8)}$.

However, investigations of factors that influence the development of nutrition knowledge from a young age are not as prominent as investigations on food preferences and dietary habits ${ }^{(9)}$. At a young age, most children are eager to learn, and they accumulate and process information by observing others, particularly parents and familiar adults such as teachers ${ }^{(10)}$. Therefore, this is a prime time for researchers to identify factors contributing to children's nutrition knowledge to optimise early intervention programmes. In order to do this, a reliable and valid measure of young children's knowledge of healthy and unhealthy food is required.

There is currently no consensus on a valid and reliable tool that can be used to measure young children's nutrition knowledge ${ }^{(11)}$. Questionnaires and interviews used with older children are not suited to the cognitive development of young children. However, the technique of using pictures has been shown in previous studies to maintain young children's interest and motivation and is appropriate for their level of cognitive development ${ }^{(11,12)}$. Therefore, the aim of the present study was to develop a photo-based activity, called the Healthy Food Knowledge Activity (HFKA), which could be used to assess the nutrition knowledge of young children. 


\section{Methods}

\section{Participants}

Children were included if they were 5-6 years of age and they and their parents consented to take part. There were no exclusion criteria for children or parents. Children were recruited from reception classes at public primary schools in the Adelaide metropolitan area. To ensure that the sample was selected from a range of socio-economic levels, the Australian Bureau of Statistics Socio-Economic Index for Areas (SEIFA) index of relative disadvantage was used to stratify schools according to socio-economic status (SES). SEIFA assigns relative indices of SES to postal areas on the basis of Census data for attributes such as income, education attainment and occupation. Postcodes for the Adelaide metropolitan area were sorted according to the SEIFA index from the most to the least disadvantaged and divided into five strata ranging from very low to very high SES. Four postcodes were randomly selected from each of those five strata, and schools from each of those postcode areas were identified. One school was then randomly selected from each of those groups and was sent information about the study. Thus, twenty schools were initially contacted in July 2008. Following initial replies from schools declining participation in the study, a further two schools were contacted from the corresponding postcode group to achieve the stratified spread of SES. Information about the study was distributed to school principals by email, including an information sheet, approval letter from the Department of Education and Children's Services (DECS) and school consent form. Written consent was obtained from the school principal or deputy principal before commencement of the study within each school. Participant information sheets, consent forms and questionnaires were distributed to parents of all students in participating classes. Written consent was obtained from all parents and verbal consent was obtained from each child. Ethical approval was obtained from the University of South Australia Human Research Ethics Committee and from the DECS Ethics Committee, and a police clearance certificate was obtained by the researcher to allow her to work with children in the schools.

\section{Healtby Food Knowledge Activity}

A list of thirty healthy and unhealthy foods and drinks was generated from the Australian Guide to Healthy Eating, a food guide developed to help Australians choose a healthy diet consisting of a range of foods from a variety of food groups $^{(13)}$ : sixteen from the five core food groups and fourteen from the list of non-core foods. A detailed list is provided in Table 2. Foods were selected with varying degrees of difficulty to be categorised as healthy or unhealthy in order to distinguish children with more complex nutrition knowledge from those who had only a basic understanding. For example, common foods that were expected to be easily categorised correctly by children were apple, carrot, broccoli, milk, lollies, chocolate and watermelon, whereas it was expected that only children with better nutrition knowledge would correctly categorise foods such as nuts, fish, orange juice, fried chicken and legumes. Other foods were considered to be of intermediate difficulty; for instance, cookies, soft drinks, hot chips, potato chips, cheese, ice cream, hot dog and corn on the cob. Colour digital photographs of all the foods and drinks were taken, printed on photo paper and laminated for durability. A green tick, red cross and blue question mark were also printed in colour and laminated for use in the activity.

A standardised script was used to ensure consistency of delivery of the HFKA. Before beginning the HFKA, the child was asked to define the terms 'healthy food' and 'unhealthy food'. The child was then given a standard definition, irrespective of whether they could initially provide a definition of the terms. For the standard definition, 'healthy food' was defined as 'food that is good for you that you should eat a lot of' and 'unhealthy food' was defined as 'food that is not good for you that you should only eat sometimes, ${ }^{,(12,14)}$. Next, the child was shown the thirty photos of foods one at a time. For each photo, the child was first asked to name the food to indicate whether they recognised the food. If the child did not know the name of the food or they named the food incorrectly, they were told the correct name of the food. If the child was hesitant about the name of the food, it was confirmed whether they were familiar with the food by asking whether they knew what the food was, had eaten it before or had seen a relative or friend eat the food. The child was then asked to say whether they thought the food was healthy or unhealthy and then to place the photo of the food next to the green tick if they thought it was healthy, the red tick if they thought the food was unhealthy or against the blue question mark if they were unable to identify the food or the answer. The option of question mark was provided to minimise errors that may arise from the child guessing the correct answer ${ }^{(11)}$.

If the child changed his/her mind about his/her answers during the course of the activity, he/she was allowed to change the answers, provided these had not been discussed during the course of the activity. If it was observed that the child was unsure how to proceed with a response, the researcher prompted the child by asking whether he/she thought the food should be eaten a lot of the time or sometimes and then re-confirming the definitions of healthy and unhealthy foods. If the child asked whether he/she had placed the food in the correct category, the researcher explained that they could not talk about the answers until they had finished looking at all the photos. The HFKA took 5-10 min to complete with each child, which is a suitable length of time for children of this age group ${ }^{(11)}$.

\section{Pilot study}

To assess the test-retest reliability, procedure and understanding of the activity by this age group, 5-6-yearold children were recruited to pilot the HFKA via an email 
distributed to staff in the Division of Health Sciences at the University of South Australia and a convenience sample within the local community of the researcher. These tests were conducted a minimum of $7 \mathrm{~d}$ apart, and up to $14 \mathrm{~d}$ because of child/parent availability. For this pilot study, parents were asked to remain outside the room so as not to influence the child's responses. The HFKA procedure was conducted with each child as described above, with the exception of some minor methodological changes resulting from the pilot study, which are described below. During the first test, a stopwatch was used to measure the length of time taken to complete the activity. Parents were asked not to discuss the activity or healthy and unhealthy foods with their child in the period between testing occasions.

The term 'often' was replaced with 'a lot of the time' in the definition of healthy as some of the children did not understand the word 'often' but understood when it was substituted with 'a lot of the time'. Initially, children were asked to indicate whether 'they should eat the food a lot of the time or sometimes' before categorising the food as healthy or unhealthy. However, some children misunderstood the question as asking how often they 'consumed' the food, and proceeded to categorise the food on the basis of this and not whether they thought it was healthy. This had to be explained to the child and when it was clear that the child understood the concept he/she was allowed to choose his/her answer again. From this, it was decided that this question should only be asked if the child was having trouble remembering the definitions of healthy and unhealthy foods, or he/she needed to be prompted to give an answer. In addition to this, to ensure that the question was interpreted correctly by the child, it was rephrased with emphasis on the words 'think' and 'should' as follows: 'Do "you think" that you "should" eat the food a lot of the time or sometimes?'

The explanation of the purpose of the question mark at the beginning of the activity was expanded to clarify that the child did not have to add a response with the question mark. Some children thought that they had performed the activity incorrectly because they did not place anything with the question mark, or children placed names of foods with the question mark because they felt that they had to place something there (rather than actually not knowing the answer). The script for the activity was changed as follows: 'If you do not know the answer you can put the photo with the question mark, but only put the photo there if you really do not know the answer. Try to have a go first. It is okay if you do not put anything with the question mark'. Finally, the photo of the muesli bar was changed to one without packaging because the children found it difficult to recognise the original photo that showed the bar in its packaging.

Responses on the HFKA were scored according to whether the child correctly assigned each food as healthy (1) or unhealthy (0), providing a nutrition knowledge score out of thirty for each child. Responses on individual items were also recorded to gain qualitative information about the foods that children thought were healthy or unhealthy.

\section{Parent questionnaire}

A self-administered parent questionnaire assessed demographic information including child's age and gender, parent's age and gender, family status, number of children in the family, residential postcode and employment status, occupation and education level of parents. Answers were indicated separately for each parent in the family (as parents 1 and 2) and the parent completing the questionnaire was asked to designate themselves as parent 1. Further questions including attitudes, beliefs and nutrition knowledge of parents were asked to determine predictors of children's nutrition knowledge, which will be reported separately.

\section{Data analysis}

Statistical analyses were conducted using the Statistical Package for the Social Sciences statistical software package version $15 \cdot 0$ for Windows (SPSS Inc., Chicago, IL, USA) and the STATA statistical software package version 10.0 (StataCorp, College Station, TX, USA). Descriptive statistics were generated and distributions of variables were checked for normality before statistical analysis. Test-retest reliability of the HFKA was determined using intra-class correlations. Differences in individual response items between girls and boys were compared using $t$ tests.

\section{Results}

\section{Pilot study}

The average score achieved in the first round of tests ( $n$ 13; nine girls and four boys) was $22 \cdot 7$ (SD 4.5), and that for the second round was 23.6 ( $\mathrm{SD} 4 \cdot 8$ ). Histograms showed that distributions of scores for both rounds of testing were normal, with skewness and kurtosis within acceptable limits ${ }^{(15)}$. The intra-class correlation between testing rounds was high $(r=0 \cdot 84 ; P=0 \cdot 03)$, indicating good test-retest reliability of the HFKA.

\section{Main study}

\section{Demographics}

The demographic characteristics of participants are summarised in Table 1. A total of 192 children (eighty-two girls and 110 boys) completed the HFKA. Most children were from two-parent households, and the majority of parents indicated that their cultural background was Australian. Only a very small percentage of participating children had special dietary requirements and this factor was not significantly associated with children's nutrition knowledge (HFKA score). 


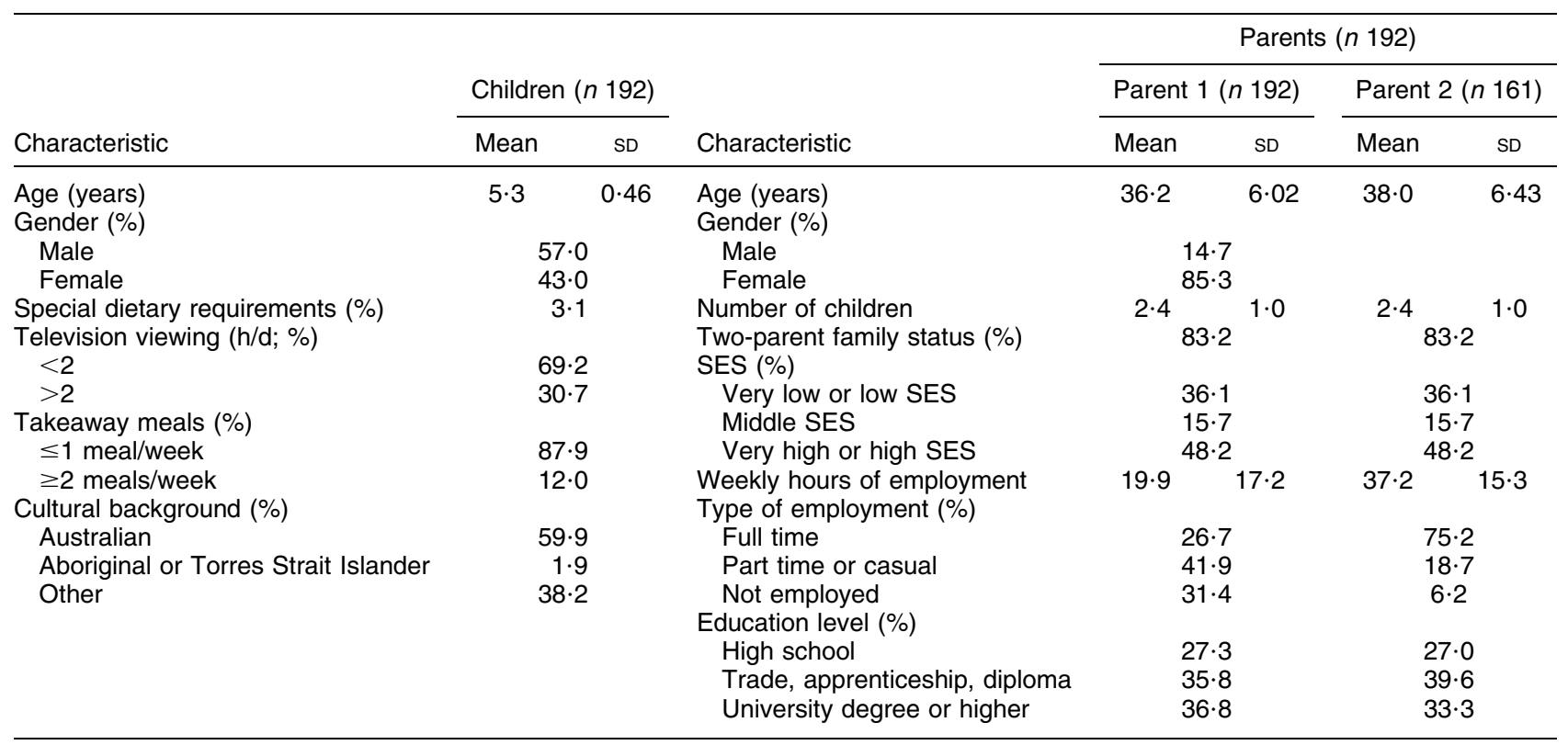

SES, socio-economic status.

Data are percentage or mean and SD. Parent 1 denotes parent who completed the questionnaire; parent 2 is the other in the family.

\section{Children's knowledge of healthy foods}

The average nutrition knowledge score on the HFKA was 23 out of a maximum score of 30 , ranging from a minimum of 9 to a maximum of 29. There was no significant difference between mean scores for girls and boys. Histogram distributions showed a small negative skew. However, standard error of skewness was small and the sample size was large; hence, this would not be expected to make a notable difference to the analysis ${ }^{(15)}$.

Table 2 shows a breakdown of how children categorised foods in the HFKA. The majority of children were able to categorise fruit and vegetables (apple, corn, broccoli, carrot and watermelon) correctly as healthy and over $80 \%$ of children categorised milk, cheese and bread correctly as healthy. In contrast, only around half of children recognised that legumes and nuts were healthy. Fish, yoghurt and orange juice were also not as commonly classified correctly, with only $60-70 \%$ of children reporting these as healthy foods.

Doughnuts, chocolate and lollies were correctly classified as unhealthy by over $90 \%$ of children. Potato chips and ice cream were also correctly classified by more than $85 \%$ of children. However, about half of children did not recognise that muesli bars, fried chicken, meat pies and coco pops were unhealthy foods, and more than half correctly identified hot dogs as unhealthy. Overall, foods that were expected to be classified more easily were more correctly classified and foods expected to be more difficult for children to classify were more incorrectly classified, indicating good face validity of the HFKA. Results of $t$ tests showed that there were no significant differences between girls and boys in correct responses for healthy foods. However, from the unhealthy foods, significantly more girls than boys incorrectly indicated that fried chicken was healthy $(P<0 \cdot 01)$.

\section{Discussion}

There is currently little consensus on a valid and reliable tool to measure young children's nutrition knowledge; thus, the aim of the present study was to develop a measurement tool with good test-retest reliability and face validity that could detect variations in responses. Findings from the HFKA showed that children as young as 5 years of age are capable of distinguishing healthy and unhealthy foods, indicating that children of this age group can benefit from nutrition education.

Previous research has determined that children as young as 3 years of age can benefit from nutrition education. Contento et al. ${ }^{(10)}$ reviewed a number of studies and found that 3-5-year-old children could identify foods, comprehend concepts of nutrients and energy value and that nutrition education with pre-school children could significantly improve their knowledge about nutrition-related concepts. Another study based in a day-care centre involving 3-5year-old children consisted of group action stories, songs, food activities and food tasting ${ }^{(10)}$, finding that such activities significantly improved the children's nutrition knowledge and particularly their ability to identify foods.

Resnicow and Reinhardt ${ }^{(16)}$ found that children aged 5-18 years could identify that some foods were healthier than others, and the majority of children thought that fruits, vegetables, wholemeal bread and cheese were 
Table 2 Summary of responses given by children for the HFKA ( $n$ 192)

\begin{tabular}{|c|c|c|c|c|c|c|c|c|c|c|c|}
\hline \multirow[b]{2}{*}{ Food } & \multicolumn{2}{|c|}{$\begin{array}{l}\text { Said healthy and } \\
\text { to eat often }\end{array}$} & \multicolumn{2}{|c|}{$\begin{array}{l}\text { Said unhealthy and } \\
\text { to eat sometimes }\end{array}$} & \multicolumn{2}{|c|}{ Did not know } & \multicolumn{2}{|c|}{$\begin{array}{l}\text { Girls said healthy } \\
\text { and to eat often }\end{array}$} & \multicolumn{2}{|c|}{$\begin{array}{l}\text { Boys said healthy } \\
\text { and to eat often }\end{array}$} & \multirow{2}{*}{$\begin{array}{l}\text { Order } \\
\text { presented } \\
\text { to child }\end{array}$} \\
\hline & $n$ & $\%$ & $n$ & $\%$ & $n$ & $\%$ & $n$ & $\%$ & $n$ & $\%$ & \\
\hline \multicolumn{12}{|l|}{ Non-core foods } \\
\hline Doughnut & & & 180 & $93 \cdot 8$ & 3 & $1 \cdot 6$ & 4 & 4.9 & 8 & $7 \cdot 3$ & 4 \\
\hline Meat pie & & & 105 & $54 \cdot 7$ & 19 & $10 \cdot 0$ & 41 & $50 \cdot 6$ & 45 & $40 \cdot 9$ & 10 \\
\hline Hot dog & & & 119 & $62 \cdot 0$ & 6 & $3 \cdot 2$ & 30 & $37 \cdot 0$ & 42 & $38 \cdot 2$ & 11 \\
\hline Potato chips & & & 171 & $89 \cdot 1$ & 0 & 0.0 & 7 & $8 \cdot 6$ & 12 & $10 \cdot 9$ & 12 \\
\hline Chocolate & & & 183 & $95 \cdot 3$ & 0 & 0.0 & 3 & $3 \cdot 7$ & 5 & 4.5 & 13 \\
\hline Lollies & & & 182 & $94 \cdot 8$ & 1 & 0.5 & 2 & $2 \cdot 5$ & 7 & $6 \cdot 4$ & 14 \\
\hline Ice cream & & & 170 & $88 \cdot 5$ & 0 & 0.0 & 8 & $9 \cdot 9$ & 13 & $11 \cdot 8$ & 17 \\
\hline Fried chicken (KFC) & & & 92 & $47 \cdot 9$ & 8 & $4 \cdot 2$ & 55 & $67 \cdot 9$ & 44 & $40 \cdot 0$ & 21 \\
\hline Cheese burger & & & 136 & $70 \cdot 8$ & 5 & $2 \cdot \overline{6}$ & 21 & $25 \cdot 9$ & 34 & $30 \cdot 9$ & 22 \\
\hline Coco pops & & & 105 & $54 \cdot 7$ & 8 & $4 \cdot 2$ & 41 & $50 \cdot 6$ & 45 & $40 \cdot 9$ & 23 \\
\hline Hot chips & & & 144 & $75 \cdot 0$ & 1 & $0 . \overline{5}$ & 15 & $18 \cdot 5$ & 32 & $29 \cdot 1$ & 24 \\
\hline Chocolate chip cookies & & & 153 & 79.9 & 4 & $2 \cdot 1$ & 12 & $14 \cdot 8$ & 26 & $23 \cdot 6$ & 25 \\
\hline Soft drink & & & 151 & $78 \cdot 6$ & 4 & $2 \cdot 1$ & 19 & $23 \cdot 5$ & 21 & $19 \cdot 1$ & 26 \\
\hline Muesli bar & & & 93 & $48 \cdot 4$ & 13 & $6 \cdot 8$ & 39 & $48 \cdot 1$ & 59 & $53 \cdot 6$ & 30 \\
\hline \multicolumn{12}{|l|}{ Core foods } \\
\hline \multicolumn{12}{|l|}{ Fruit and vegetables } \\
\hline Apple & 190 & $99 \cdot 0$ & & & 0 & 0.0 & 81 & $100 \cdot 0$ & 108 & $98 \cdot 2$ & 1 \\
\hline Corn on the cob & 176 & $91 \cdot 7$ & & & 5 & $2 \cdot 6$ & 72 & 88.9 & 103 & $93 . \overline{6}$ & 3 \\
\hline Broccoli & 177 & $92 \cdot 2$ & & & 2 & $1 \cdot 1$ & 74 & $91 \cdot 4$ & 102 & $92 \cdot 7$ & 9 \\
\hline Carrot & 178 & $92 \cdot 7$ & & & 2 & $1 \cdot 1$ & 74 & $91 \cdot 4$ & 103 & $93 \cdot 6$ & 16 \\
\hline Orange juice & 116 & $60 \cdot 4$ & & & 5 & $2 \cdot 6$ & 48 & $59 \cdot 3$ & 68 & $61 \cdot 8$ & 18 \\
\hline Watermelon & 181 & $95 \cdot 3$ & & & 1 & 0.5 & 78 & $96 \cdot 3$ & 104 & 94.5 & 20 \\
\hline \multicolumn{12}{|l|}{ Meat and alternatives } \\
\hline Fish & 118 & $61 \cdot 5$ & & & 16 & $8 \cdot 3$ & 49 & $60 \cdot 5$ & 68 & $61 \cdot 8$ & 2 \\
\hline Eggs & 152 & $79 \cdot 2$ & & & 10 & $5 \cdot 3$ & 64 & $79 \cdot 0$ & 88 & $80 \cdot 0$ & 5 \\
\hline Nuts & 90 & $46 \cdot 9$ & & & 15 & $7 \cdot 9$ & 40 & $49 \cdot 4$ & 49 & $44 \cdot 5$ & 19 \\
\hline Legumes (beans) & 109 & $56 \cdot 8$ & & & 13 & $6 \cdot 8$ & 51 & $63 \cdot 0$ & 57 & $51 \cdot 8$ & 29 \\
\hline \multicolumn{12}{|l|}{ Cereals } \\
\hline Brown rice & 150 & $78 \cdot 1$ & & & 12 & $6 \cdot 3$ & 64 & $79 \cdot 0$ & 85 & $77 \cdot 3$ & 6 \\
\hline Bread & 165 & $85 \cdot 9$ & & & 7 & $3 \cdot 7$ & 74 & $91 \cdot 4$ & 90 & $81 \cdot 8$ & 7 \\
\hline Cereal (Just Right) & 158 & $82 \cdot 3$ & & & 7 & $3 \cdot 7$ & 68 & $84 \cdot 0$ & 89 & $80 \cdot 9$ & 15 \\
\hline \multicolumn{12}{|l|}{ Dairy foods } \\
\hline Yoghurt & 136 & $70 \cdot 8$ & & & 7 & $3 \cdot 7$ & 56 & $69 \cdot 1$ & 79 & $71 \cdot 8$ & 8 \\
\hline Cheese & 161 & 83.9 & & & 4 & $2 \cdot 1$ & 65 & $80 \cdot 2$ & 95 & $86 \cdot 4$ & 27 \\
\hline Milk & 177 & $92 \cdot 2$ & & & 4 & $2 \cdot 1$ & 70 & $86 \cdot 4$ & 106 & $96 \cdot 4$ & 28 \\
\hline
\end{tabular}

HFKA, Healthy Food Knowledge Activity. 
healthy, whereas chocolate, fries and ice cream were unhealthy. Earlier studies have shown that 7-year-old children understand the main attributes of foods; for example, that apples, carrots and milk contain vitamins and potato chips contain salt and fat ${ }^{(12)}$. The same study found that children could discriminate foods well and were able to group foods together on the basis of common elements. An earlier study also showed that children were able to discriminate foods that were 'good for you' from foods that were 'bad for you' and on a simplistic level could explain why this was so ${ }^{(17)}$. A review of Dutch children's nutrition knowledge also found that many children aged $6-8$ years could correctly identify healthy foods, with $>90 \%$ recognising that consumption of fruit and vegetables is important for health, and $<40 \%$ identifying fast food or soft drink as healthy ${ }^{(18)}$. This shows that pre-school-age children can benefit from nutrition education in order to increase their knowledge about foods, and starting nutrition education from this young age may help to form positive attitudes about food that may be maintained as children grow older.

The rate of correct responses for fruit and vegetables was higher than for all other foods. Children's main source of information about fruit and vegetables is likely to be their parents; however, children's fruit and vegetable knowledge may have also been influenced by recent state and national government campaigns in Australia to increase fruit and vegetable consumption. The Go for $2 \& 5^{\mathrm{TM}}$ campaign, which children may be exposed to through television viewing in the home and print media of the campaign at school or pre-school, aims to increase knowledge about dietary recommendations for fruit and vegetables in the Australian population ${ }^{(19)}$. A study involving Western Australian adults showed that the campaign significantly increased knowledge about dietary recommendations of fruit and vegetables by $11.5 \%$ and $23.5 \%$, respectively ${ }^{(19)}$. Children's fruit and vegetable knowledge may also be influenced by the Crunch\&Sip ${ }^{\mathrm{TM}}$ campaign run in many Australian primary schools, implementing a break during morning lessons for children to eat fruit and vegetables. However, not all schools in the present study implemented this programme and children had only limited exposure to the campaign, having been at school for $<1$ year when the present study took place.

Children showed less understanding of the health benefits of nuts, fish and legumes. On account of the severity of some nut allergies, many schools do not allow nuts or foods with nuts at school, and this may negatively influence children's perception of nuts. Parents may also be less likely to provide nuts to their children as they may perceive them to be expensive to purchase and to contain a large amount of fat ${ }^{(20)}$. Only about half of children identified fish and legumes as healthy and 7-10\% of children did not know the answer or did not recognise these foods (particularly legumes). These two foods are promoted as good alternatives to red meat; yet, children's lack of recognition of these as healthy suggests that wider marketing is needed ${ }^{(13)}$. In particular, wider promotion of legumes is needed as only $23 \%$ of adults and $5-7 \%$ of children in Australia consume legumes ${ }^{(21)}$. The nutritional profile of legumes can provide many health benefits to children, and increasing consumption from an early age can form dietary patterns that may persist throughout life and thereby contribute to long-term health benefits. Greater consumption may be achieved by addressing factors that can discourage the use of legumes, including concerns about flatulence and gastrointestinal upset and a lack of knowledge about preparation and recipes incorporating legumes ${ }^{(20,21)}$.

Foods from the 'unhealthy' category that were classified correctly most of the time include doughnuts, chocolate and lollies. Overall, children's ability to recognise foods that were unhealthy was similar to the recognition of healthy foods. However, almost half of the children thought that muesli bars, fried chicken, meat pies, hot dogs and coco pops were healthy. This may be a result of how readily these foods are available to children and misconceptions about these foods as a result of misleading marketing. For instance, television advertising of some sweetened breakfast cereals implies that they are healthy because they are served with milk and this can be misleading for children. It may be as a result of this type of advertising that many children in the present study believed that coco pops are healthy. Likewise, muesli bars, commonly high in fat and sugar, are often misconceived as healthy because of the way they are marketed, and may therefore be seen by parents as healthy snack food for children. Meat pies and hot dogs are readily available for young children to consume in school canteens, at sporting events and special events such as carnivals and fetes, and this widespread availability may influence children's perception of these foods as healthy.

It is encouraging to note that most children correctly identified other unhealthy foods such as soft drinks, cookies and ice cream as unhealthy. Hot chips were identified correctly as unhealthy by most children; however, one-third of boys said that they were healthy. Children of this age may perceive hot chips to be healthy as they are made from potatoes and because they do not understand that cooking processes can have an effect on the nutrient content and energy density of foods. This may also be the case for fried chicken, with young children not being able to make the distinction that, although chicken is a healthy meat to consume, the process of battering and deep frying makes fried chicken unhealthy. Interestingly, about $30 \%$ of children identified yoghurt as unhealthy. This may be due to the high sugar content and sweet taste of some yoghurts, which can resemble foods such as ice cream and sweets that are considered unhealthy. Consequently, it should be noted that some children's understanding of healthy and unhealthy foods may be influenced by the food's sensory properties and therefore by the child's preference for the food ${ }^{(17)}$. Although this was 
minimised in the present study by the administration and explanation of the HFKA, it may influence children's categorisation of unhealthy foods as healthy.

The present study found no gender differences in correct responses given by children, except for fried chicken, which significantly more girls than boys incorrectly classified as healthy. It is also interesting to note that there were minimal gender differences and that girls, if anything, had slightly lower nutrition knowledge scores than boys. This is in contrast to previous literature, which found that girls achieved $85 \%$ accuracy compared with only $65 \%$ accuracy for boys in a sample of 7-11-year-old children ${ }^{(14)}$.

Generalisability of the results may be limited by a selfselection bias because participants who volunteered for the study may have a greater interest in nutrition and may therefore place greater importance on teaching their children about healthy food than the general public. We minimised this possibility by stratified SES sampling and provision of movie tickets for completed questionnaires. There was a small negative skew in HFKA scores, which may indicate that some foods were too easy for children to categorise. Hence, further development and validation of the HFKA with more difficult food choices may strengthen this methodology. Future research should also explore whether knowledge of healthy and unhealthy foods is associated with consumption of those foods.

In conclusion, the HFKA is a useful activity for identifying young children's knowledge of healthy and unhealthy foods, which can be used by researchers and educators to determine the predictors of nutrition knowledge as well as the effectiveness of health education programmes targeted at this age group. The results of the present study show that children in early primary school can be targeted effectively for nutrition education. The breakdown of children's responses indicates areas in which their knowledge of foods is lacking, and these should be targeted when educating children about food and nutrition.

\section{Acknowledgements}

The present research received no specific grant from any funding agency in the public, commercial or not-for-profit sectors. However, the present study was supported by existing funding to provide movie tickets for participating parents from the University of South Australia SA Fellowship support scheme. There is no conflict of interest to be disclosed. D.Z., J.D. and N.S. collaborated on the development of the HFKA; D.Z. collected the data; D.Z. and N.S. prepared the manuscript. All authors contributed equally to the analysis of data and editing of the manuscript. The authors thank all school principals and teachers, as well as all parents and children who assisted with the present study.

\section{References}

1. Campbell KJ \& Hesketh KD (2007) Strategies which aim to positively impact on weight, physical activity, diet and sedentary behaviours in children from zero to five years. A systematic review of the literature. Obes $\operatorname{Rev} \mathbf{8}, 327-338$.

2. Wardle J (1995) Parental influences on children's diets. Proc Nutr Soc 54, 747-758.

3. Backman DR, Haddad EH, Lee JW et al. (2002) Psychosocial predictors of healthful dietary behavior in adolescents. J Nutr Educ Behav 34, 184-193.

4. Branen L \& Fletcher J (1999) Comparison of college students' current eating habits and recollections of their childhood food practices. J Nutr Educ 31, 304-310.

5. Axelson ML, Federline TL \& Brinberg D (1985) A metaanalysis of food and nutrition-related research. J Nutr Educ 17, 51-54.

6. Sasser KA, Hoelscher DM, Scheurer ME et al. (2005) Nutrition knowledge and dietary behavior of school-age children in Texas who participated in the school physical activity and nutrition project. J Am Diet Assoc 105, 8 Suppl. 1, 20.

7. Wardle J, Parmenter K \& Waller J (2000) Nutrition knowledge and food intake. Appetite 34, 269-275.

8. Worsley A (2002) Nutrition knowledge and food consumption: can nutrition knowledge change food behaviour? Asia Pac J Clin Nutr 11, Suppl. 3, S579-S585.

9. Gibson EL, Wardle J \& Watts CJ (1998) Fruit and vegetable consumption, nutritional knowledge and beliefs in mothers and children. Appetite 31, 205-228.

10. Contento IR (editor) (1995) The effectiveness of nutrition education and implications for nutrition education policy, programs and research - a review of research. J Nutr Educ 27, 279-418.

11. Owen S, Schickler P \& Davies J (1997) Food choice: how to assess attitudes of pre-adolescent children. Nutr Food Sci 97, 5-11.

12. Magarey M, Worsley A \& Boulton J (1986) Children's thinking about food: 1. Knowledge of nutrients. J Food Nutr 43, 2-9.

13. Smith A, Kellet E \& Schmerlaib Y (1998) The Australian Guide to Healthy Eating. Canberra: Department of Health and Ageing, Australian Government.

14. Hart KH, Bishop JA \& Truby H (2002) An investigation into school children's knowledge and awareness of food and nutrition. J Hum Nutr Diet 15, 129-140.

15. Hair JF, Anderson RE, Tatham RL et al. (1998) Multivariate Data Analysis. Upper Saddle River, NJ: Prentice-Hall Inc.

16. Resnicow K \& Reinhardt J (1991) What do children know about fat, fiber and cholesterol? A survey of 5,116 primary and secondary school students. J Nutr Educ 23, 65-71.

17. Magarey M, Worsley A \& Boulton J (1986) Children's thinking about food: 2 . Concept development and beliefs. J Food Nutr 43, 9-16.

18. Westenhoefer J (2002) Establishing dietary habits during childhood for long-term weight control. Ann Nutr Metab 46, 18-23.

19. Pollard CM, Miller MR, Daly AM et al. (2007) Increasing fruit and vegetable consumption: success of the Western Australian Go for $2 \& 5$ campaign. Public Health Nutr 11, 314-320.

20. Lea E, Worlsey A \& Crawford D (2005) Australian adult consumers' beliefs about plant foods: a qualitative study. Health Educ Behav 32, 795-808.

21. Go Grains Health \& Nutrition Ltd (2010) The Grains \& Legumes Health Report. Spit Junction, NSW: G. Grains; available at http://www.gograins.com.au/pdfs/Go+Grains+ Report+22.04.10.pdf 